\title{
Case study of electrical resistivity tomography measurements used in landslides investigation, Southern Poland
}

\author{
Magdalena Mita $^{1 *}$, Michał Glazer $^{2}$, Radosław Kaczmarzyk ${ }^{1}$, \\ Michał Dąbrowski ${ }^{3}$, Karolina Mita ${ }^{1}$
}

${ }^{1}$ Science Student Society of Geophysics PREM, Faculty of Earth Sciences, University of Silesia, Będzińska Str. 60, 41-200 Sosnowiec,

${ }^{2}$ Department of Geomorphology, Faculty of Earth Sciences, University of Silesia, Będzińska Str. 60, 41-200 Sosnowiec

${ }^{3}$ Department of Geology and Hydrogeology, Faculty of Earth Sciences, Nicolaus Copernicus University, Lwowska Str. 1, 87-100 Toruń

*Corresponding author: magdalenamita@gmail.com

Received: $4^{\text {th }}$ May, 2018

Accepted: $12^{\text {th }}$ May, 2018

\begin{abstract}
Mass movements are an ever present threat to building construction, water management, vegetation formation and biodiversity. This paper presents an approach to landslides research based on non-invasive geoelectrical method - Electrical Resistivity Tomography (ERT). Mapping and displacement monitoring of unstable slopes is crucial for the hazards prevention and assessment. The ERT technique is an effective tool to obtain structural differentiation of geological medium through interpretation of $2 \mathrm{D}$ electrical resistivity models. The main advantage of the method is a wide range of applicability what makes its useful during field works on a landslide. It is commonly used for measurements of slope instability, determination of shear surface, landslide susceptibility, depth of bedrock, slip plane geometry.

The aim of the work is to identify the geological structures underneath three selected landslides in south Poland: in Racibórz, Milówka and Porąbka. Attempts have been focused on determination of the usefulness of the proposed ERT methodology for evaluation of possible further development of mass movements. On two investigation sites two different arrays have been used: Wenner-Schlumberger and dipole-dipole which allowed to prepare combined data set and resistivity models based on them. Forward modelling of synthetic models based on a priori information allowed to understand anomalies present on resistivity models. Applied approach ensured quality increase of final interpretation of resistivity models.
\end{abstract}

Key words: Electrical Resistivity Tomography, ERT, numerical modelling, landslide, mass movements

\section{Introduction}

Landslides and areas threatened by mass movements occur throughout Poland, but most of them (over 95\%) is located in the Polish flysch Carpathians which occupy only $6 \%$ of the country. The cliffs of the Baltic coast, valleys of large rivers and places where the rivers form deeply indented valleys with steep slopes are also places where mass movements can occur. Landslides occur also sporadically in lake districts, in the Sudetes Mountains and on their foreland, in the Świętokrzyskie Mountains, in the area of the Lublin Upland and in Roztocze in West Pomeranian Voivodeship (Poprawa and Rączkowski 2003).

The main causes of landslides in Poland are the geological structures of the areas and their morphology, heavy and/or long-term atmospheric precipitation and thoughtless destructive human activities. Water that penetrates into the depths of the slip, where it 
forms a layer that facilitates the movement of rock material, is one of the primary causes for the formation or further development of a landslide (Bardel 2012). The velocity of a landslide is characterized by a wide range. The shift can be almost imperceptible, but it can also occur as a rapid avalanche at velocity up to 150 m/s (Mizerski 2000).

The geological structure and morphology have the greatest impact on the formation of landslides in the Carpathian region. They have high and steep slopes of valleys and flysch geological structure (alternating layers of waterpermeable sandstone and poorly permeable shale, claystone and marl). It is also possible to observe the presence of wide rock waste susceptible to landslide processes, and tectonic structures which create favourable conditions for mass movements (rock layers, cracks, faults) (Poprawa and Rączkowski 2003).

Geophysical methods are developing extremely fast along with the advancement of computer technology, including data processing and digital transmission. They are effective because they allow to recognize the relatively large areas quickly and in a continuous manner compared, for example, to local (point) recognition like borehole, shaft or excavation. Common methods used during field works on landslides are the ground-penetrating radar (GPR), seismic methods in 2D and 3D (seismic refraction profiling), seismic tomography, multichannel analysis of surface waves (MASW) and seismic interferometry as well as electrical resistivity profiling and electrical resistivity tomography (ERT) (e.g. Sass et al. 2007; Marescot et al. 2008; Pánek et al. 2008; Chambers et al. 2010; Calamita et al. 2013; Jebur et al. 2014; Pilecki and Harba 2015; Marinescu et al. 2017). Other methods are: the electromagnetic terrain conductivity method, reflection seismic, microgravimetry and remote sensing methods (Pilecki and Pilecka, 2016).

Electrical resistivity tomography has a wide range of applicability what makes its useful during field works on a landslide. It is non- invasive and allows to obtain spatial information about the structure of the geological medium. It is used, for example, for measurements of the various types of slope deformations in bedrock, slope instability, determination of shear surface, landslide susceptibility, depth of bedrock, slip plane geometry and compositional variations (e.g. Friedel et al. 2006; Jomard et al. 2007; Marescot et al. 2008; Pánek et al. 2008; Grandjean et al. 2011; Malehmir et al. 2013; Chen et al. 2014; Dostal et al. 2014). It works most effectively in highly conductive medias such as loamy soils. It also allows to monitor the landslides and to conduct works to determine their activity.

Therefore, the aim of the study is to identify the geological structure underneath three selected landslides in south Poland: in Racibórz, Milówka and Porąbka, and to determine the usefulness of the proposed ERT methodology for evaluation of possible further development of mass movements. The paper presents the results obtained during field works, discussion and interpretation. Field measurements were made using the equipment of the Swedish company ABEM Terrameter LS Lund Imaging using the Wenner-Schlumberger array, showing moderate sensitivity to vertical and horizontal changes of electrical resistivity, and the dipoledipole array characterized by high sensitivity to horizontal changes. The equipment included a Terrameter - resistivity and IP instrument with integrated PC for full control of data acquisition process and storage of data, an electrode selector, a field cable set with electrodes and cable jumpers. Each resistivity cross-section was obtained after the robust inversion using RES2DINV software.

\section{Sites characterization}

The first research area was located in Racibórz in the Silesian Voivodship in the Brzezie district, located approximately $3 \mathrm{~km}$ from the central point of the city (Fig. 1A). The area belongs to the Rybnik Plateau, and in terms of 
tectonics to the Silesian-Cracow Depression. It is a seasonal landslide. In 2011 its area was 7.35 ha, length was $276 \mathrm{~m}$, and width was $320 \mathrm{~m}$. The height of the landslide was $36 \mathrm{~m}$ and the average slope gradient was $7^{\circ}$. The head scarp of the landslide was $8 \mathrm{~m}$ high and its slope was $40^{\circ}$. The rock layer consists of gravel, sand and loam (Miocene deposits) partially covered by Pleistocene deposits - fluvioglacial sand and gravel. The landslide debris consists of clay, clay-loam soil, sand and gravel. The cause of the landslide movement were natural erosion, undercutting, rainwater and meltwater infiltration. There were five minor scarps in the area of the main body of the landslide slope which were up to $4 \mathrm{~m}$ high and are clearly visible on the map of inclination angle in Figure 2A. In the area of the foot there were also surface streams. Within the landslide area change of the direction of slope aspect is noticeable (Fig. 2C). In these places, in the lower part of the landslide, there are endorheic hollows in which water accumulates after rainfall. The landscape was dominated by spruces and oaks (Sikora et al. 2011). Research on the landslide in Racibórz was carried out in 2016.

The second research area was the landslide in Milówka in the Żywiec district in the Silesian Voivodeship (Fig. 1B). It occured in the lower and middle part of the southern slope of the Prusów Mountain in the area of the Siedloki housing estate. The area belongs to the Romanki Range and the Magura Nappe. In terms of hydrogeology, the area belongs to the catchment area of Salomonka (Milówka) and Soła rivers. The landslide has been fully active since 2010. The natural infiltration of rainwater and snowmelt was determined as the main cause of the landslide motion. The area of the landslide in 2016 was 11.56 ha, its length was $468 \mathrm{~m}$ and the width was $273 \mathrm{~m}$. The height of the landslide was $127 \mathrm{~m}$ and the average slope gradient was $24^{\circ}$. The head scarp of the landslide was from 4 to $12 \mathrm{~m}$ high and its slope was $38^{\circ}$.
The rock layer consists of Miocene deposits - shale and sandstone of Hieroglyphic layers and Oligocene deposits - sandstone and shale (Magurian layers). Landslide debris consists of sandstone blocks, clay and clay with rubble. The deposition of layers is opposite to the slope (Burtan et al. 1956). The tectonic structure of the area is characterized by folding and faulting. The main scarp was 8 to $12 \mathrm{~m}$ height. Within the area of the landslide there were many minor scarps (up to $4 \mathrm{~m}$ in height) and systems of fissures and cracks as well as numerous depressions visible in Figure 3A. The toe of the landslide reached the bed of the Milówka stream and caused its clenching and destroying 150 meters of the district road. Within the landslide area signs of surface water, groundwater and springs were visible. In the area of the slope below the landslide and on its sides there was a surface watercourse, and in the area of the colluvium there were numerous wetlands and springs.

The main scarp of the landslide is structurally related to the outcrop of sandstone. Approximately $300 \mathrm{~m}$ in the NE direction in Figure $3 \mathrm{~A}$ there is another landslide that begins along the same structural surface. However, this one is much older and stabilized as evidenced by smoothed terrain surface (3A-3C). Furthermore, due to the character of the surface of this part of the slope it can be assumed that these movements could take place in two separate episodes as opposed to the research area in which undercutting the slope with the stream caused slipping down to the mentioned structural edge.

In addition, in the area of landslide there are shrubs and forest, meadows, pastures and arable lands as well as residential buildings and farm dwellings. There is also a district road, power and telephone lines and waterworks. In 2010, when the landslide occurred, the above mentioned areas have been destroyed. After that the section of the district road was rebuilt, the stream bed was strengthened, roadside ditches were made and the slopes over the section of the 


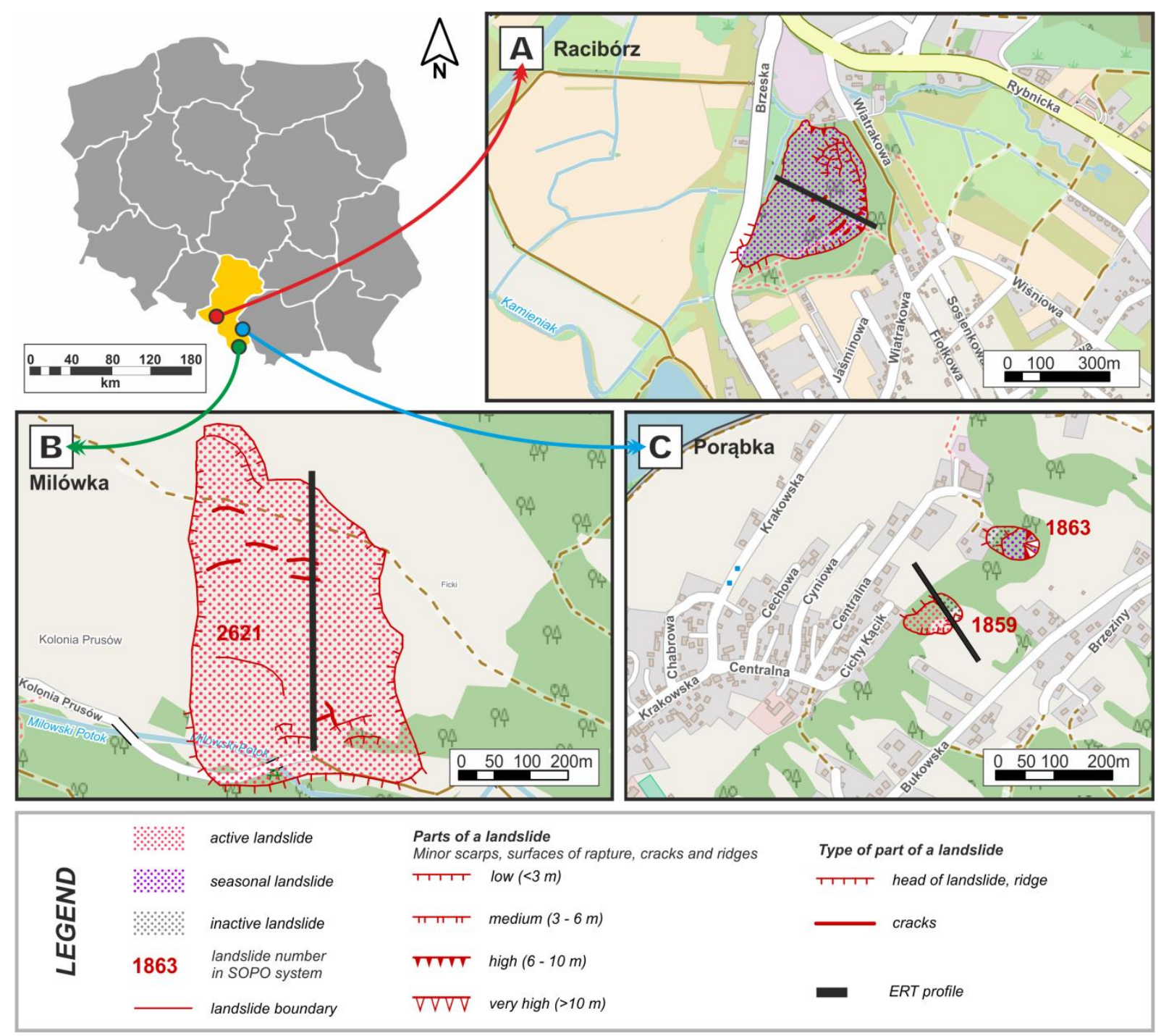

Fig.1. Location of research areas, southern Poland. (A) Landslide in Racibórz. (B) Landslide in Milówka.

(C) Landslide in Porąbka. Red line: landslide boundary. Black line: ERT profile.

new road were reinforced with stone. Due to the type of landslide and the nature of its movement it is estimated that further mass movements can occur (Rączkowski et al. 2016). Research on the landslide in Milówka was carried out in 2015.

The third research area was the landslide in Porąbka near Międzybrodzie Bialskie in the Silesian Voivodeship (Fig. 1C). It is located in the north-western part of the slope of Bukowski Gron. The length of the landslide was approximately $63 \mathrm{~m}$ and the total width is $93 \mathrm{~m}$. Within it, two parts with different levels of activity were distinguished - the active part of the landslide was $69 \mathrm{~m}$ wide and the inactive part was $24 \mathrm{~m}$ wide. The height of the landslide was $45 \mathrm{~m}$ and the average slope gradient was $36^{\circ}$ (Fig. 4B). The rock layer consists of Cretaceous flysch deposits - shale with sandstone and siderite layers (Wierzowskie layers). Their angle of inclination is $24^{\circ}$ and the slip is perpendicular to the direction determined by downcutting streams (Fig. 4). Landslide debris consists of loam, clay, clay with rock rubble, pebbles and rock blocks (based on Nescieruk and Wojcik 1997). There are cracks and fissures on the area of the landslide (Fig. 4). Research on the landslide in Porąbka was carried out in 2015. 


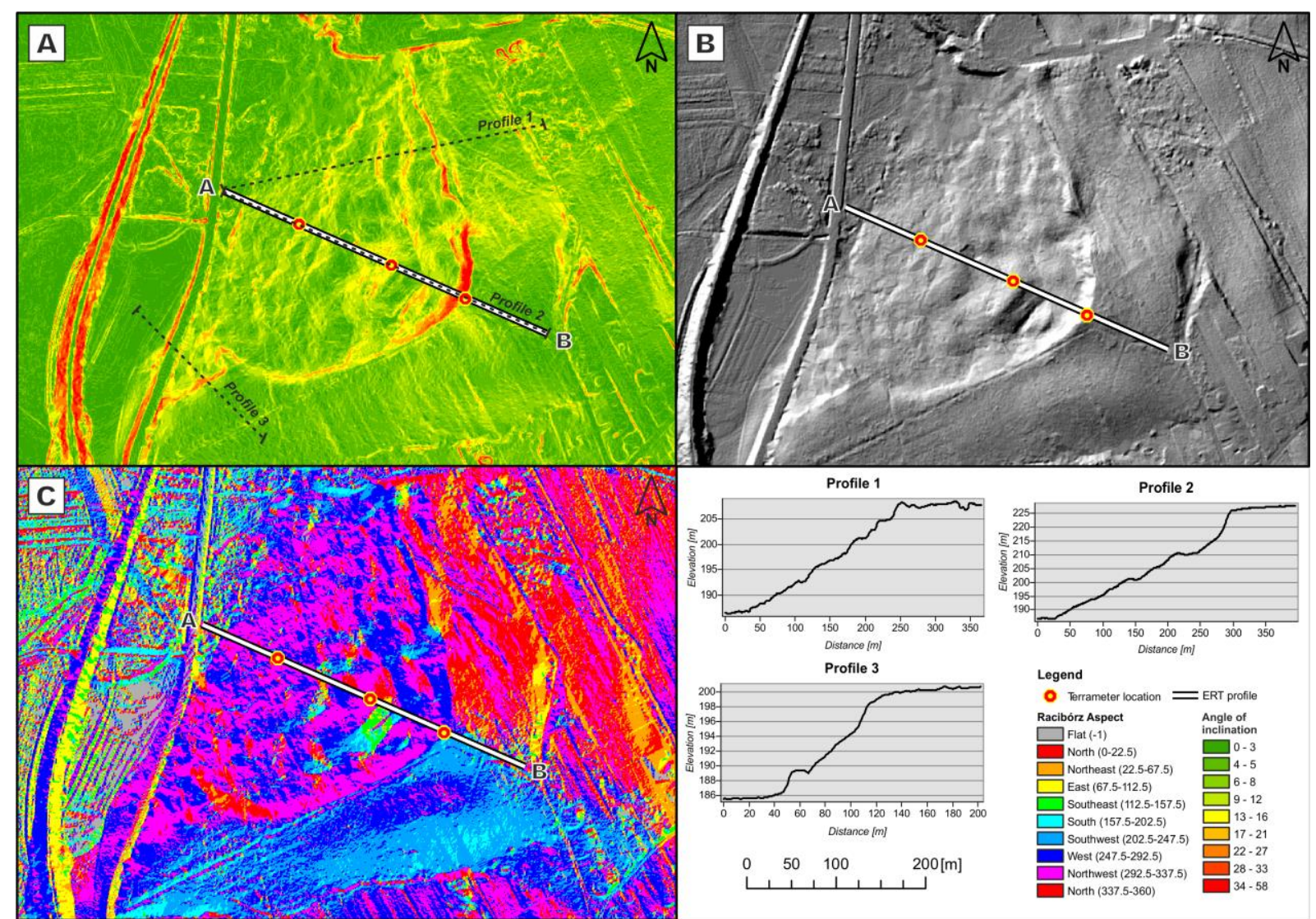

Fig.2. Raster maps of parameters of Racibórz landslide. (A) Slope inclination in $\left[{ }^{\circ}\right.$ ]. (B) Hillshade map.

(C) Aspect map.

\section{Survey method}

Electrical Resistivity Tomography (ERT or DCtomography) is a geoelectric method commonly used to obtain $2 \mathrm{D}$ or $3 \mathrm{D}$ images with high resolution variability of electrical resistivity of a geological medium. This technique is based on measurements of the distribution of apparent resistivity and changes in the electric field that has been generated artificially through a system of electrodes. The basis of this method is tracking changes in electric field using electrodes supplied with direct current (Pasierb 2012).

Depending on the purpose of the research the electrodes can be placed in various configurations (arrays). Usually four-electrode Wenner-Schlumberger array is used. It consists of two current electrodes and two potential electrodes located on one straight line. In addition, for dipole-dipole array both pairs of electrodes - current electrodes and potential electrodes are put in a line and are located from each other at a distance 'na' where ' $n$ ' is a dipole separation factor and ' $a$ ' is the spacing between the two electrodes from one pair (Lowrie 2007; Loke 2016). Then, according to Ohm's law, apparent resistivity of rocks is determined within the generated electric field, which characterizes inhomogeneous geological medium. The apparent electrical resistivity is the resultant value from the distribution of the resistivity in the medium (Parasnis 1986; Telford et al. 1990). Then, the data is processed using inversion methods to obtain a resistivity model that presents the study area in 2D. Appropriate parameters are changed based on knowledge about the geological structure of the study area, which allows to select the resistivity models that give the best representation of the actual characteristics of the studied geological medium. 


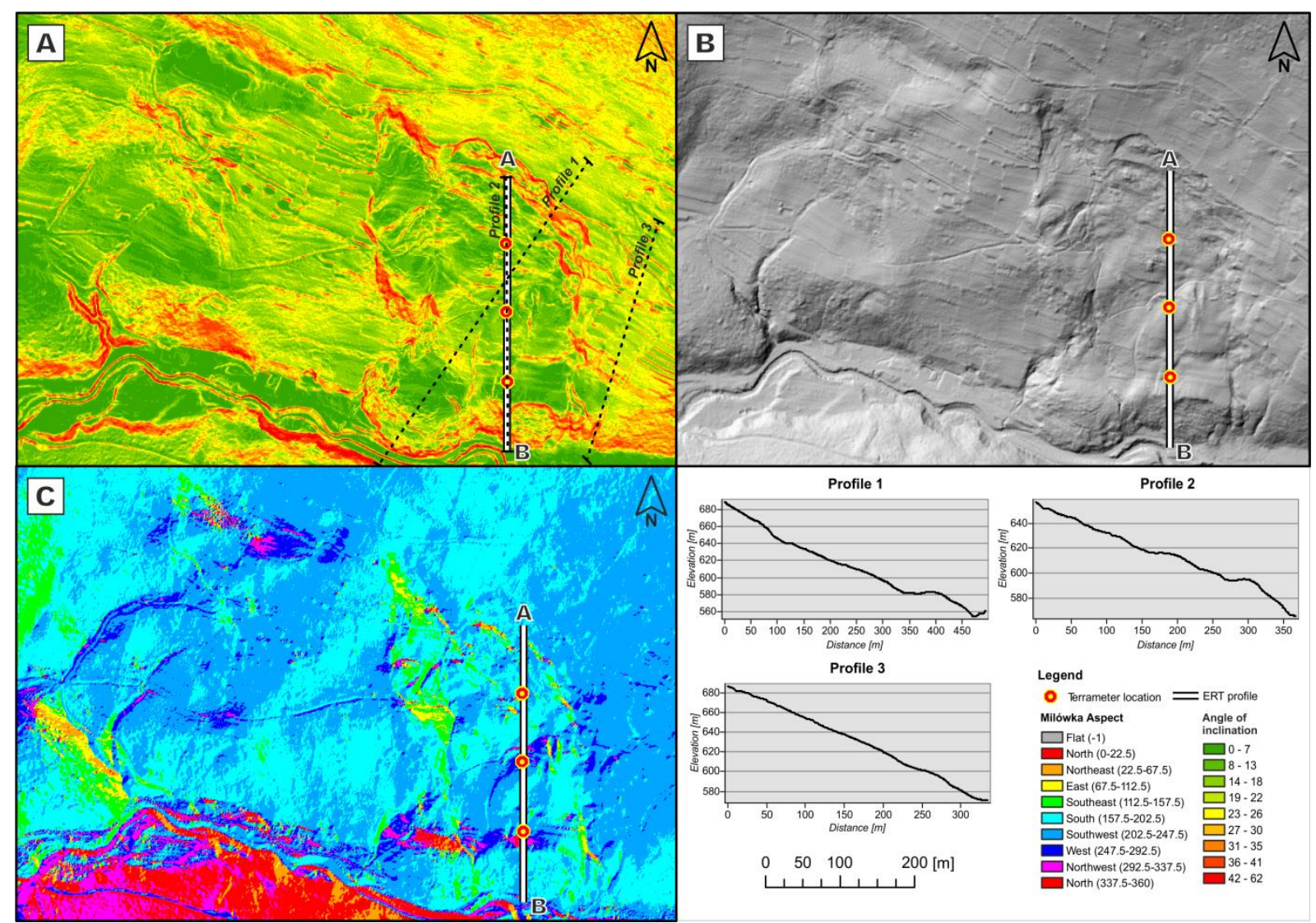

Fig.3. Raster maps of parameters of Milówka landslide. (A) Slope inclination in [ ${ }^{\circ}$ ]. (B) Hillshade map. (C) Aspect map.

The ERT technique combines electrical profiling (measurements along the profile) and vertical electrical sounding (deeper penetration of the medium with larger electrode spacing). The number of measurements corresponds to several profiling measurements with arrays with different depth ranges and several vertical electrical soundings with different maximum length of the profile line. The measurements are carried out in continuous manner with automatic selection of combination of four electrodes (Everett 2013).

The depth of penetration depends on the used measuring array and can range from $1 / 3$ to $1 / 6$ of the distance between the first and last electrode. The depth of penetration is also affected by the characteristics of the medium which depends on, for example, humidity, porosity or salinity (Loke 2015). Due to the higher spatial resolution of the ERT method it is possible to use $2 \mathrm{D}$ inversion in interpretation.
The advanced computational techniques allow to limit the ambiguity of solutions and help to obtain a two-dimensional distribution of the apparent resistivity of the medium as close as possible to the distribution of real resistivity (Loke and Barker 1996).

A geoelectric profile in the area of the landslide in the Brzezie district in Racibórz was carried out in 2016 with the WennerSchlumberger and dipole-dipole arrays. The length of the Wenner-Schlumberger profile was $300 \mathrm{~m}$ and the dipole-dipole profile was $400 \mathrm{~m}$. The electrode spacing was $5 \mathrm{~m}$. The profile on the landslide in Milówka was carried out only with the Wenner-Schlumberger array. The length of the profile was $400 \mathrm{~m}$ and the electrode spacing was $5 \mathrm{~m}$. The profile on the landslide in Porąbka was made in two configurations: Wenner-Schlumberger and dipole-dipole. The length of the profile in both cases was $200 \mathrm{~m}$ and electrode spacing was $5 \mathrm{~m}$. 


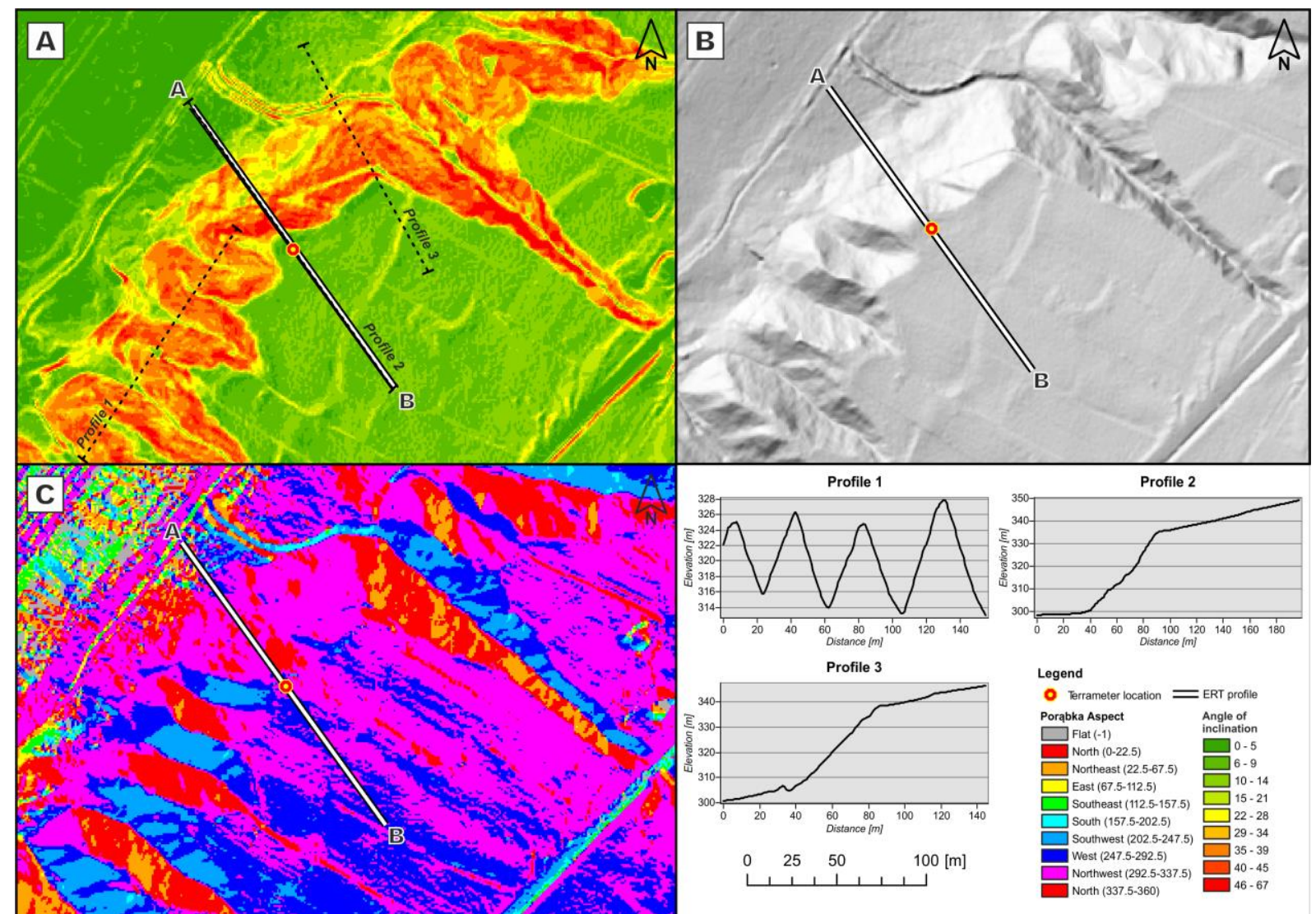

Fig.4. Raster maps of parameters of Porąbka landslide. (A) Slope inclination in $\left[^{\circ}\right]$. (B) Hillshade map.

(C) Aspect map.

\section{Data processing}

The collected data were processed using the RES2DINV software, which automatically generates a $2 \mathrm{D}$ resistivity inversion section representing variations in electrical properties of the subsurface features (Loke 2016). Inversion of field data was carried out for each profile after removing the measuring points with the highest error in row data. 24 different settings of data inversion procedure were proceed. Used configurations allowed for a detailed analysis and selection of the most optimal settings for final resistivity profiles. The most optimal setting among the configurations was the application of L1 norm (robust/blocky) for the data inversion constrain and the L2 norm (smooth) to model inversion constrain. Moreover, for the landslides of Racibórz and Porąbka combined data sets were created for the inversion procedure using
Wenner-Schlumberger and dipole-dipole field data.

The standard data constraint inversion method attempts to minimize the square of difference between the measured and calculated apparent resistivity values while the robust data constraint method attempts to minimize the absolute difference between above mentioned values. The L2 norm works well if the data contains random or 'Gaussian' noise. If the data set constrains noise from non-random sources the 'outliners' can be reduced with the L1 norm inversion method. This proves particularly useful in case of rough terrain and problems with stabilization of electrodes in the ground. However, in order to 'examine' the space of all available resistivity models - the model inversion constrain (L2 norm) is recommended where subsurface resistivity changes in a smooth manner, but when the subsurface bodies have sharp boundaries L1 norm gives more 
reliable results (Loke 2016). Unfortunately, in this case L1 norm tends to absorb smaller changes in electrical resistivity of models in favour of the massive structures which in presented cases should be considered as a loss of useful information.

Resistivity data inversions for each profile were stopped on $5^{\text {th }}$ iteration. In most cases absolute error decreased below 5\%. This value was set as an acceptable level of the error. It was assumed that the global minimum had been reached because in the 6th and 7th iteration the mean absolute errors were not changed much. The topography information is included as the elevation for each electrode in every data line.

\section{Numerical modelling}

Numerical modelling was carried out using the RES2DMOD software which allows to solve a forward problem for given resistivity model of the geological medium. This medium consists of homogeneous blocks forming a grid, and for each of them the specific value of electrical resistivity is assigned. RES2DMOD allows to select the electrode configuration, set the 'a' and ' $n$ ' values and determine the maximum depth of penetration of the medium. For a selected array using the finite difference method or the finite element method, it is possible to determine the electric potential value for each of the grid nodes. In the next stage, the value of apparent resistivity that can be measured for the given model is calculated (Loke 2016).

In the paper numerical modelling was made for two profiles characterized by $400 \mathrm{~m}$ length and $5 \mathrm{~m}$ electrode spacing. On its basis, it was possible to separate inversion artefacts from natural geological features present on resistivity profiles obtained from field data.

For the first profile for the parallel layers located in the low-resistivity medium $(55 \Omega \mathrm{m})$ three different values of electrical resistivity were assumed: $300 \Omega \mathrm{m}, 1000 \Omega \mathrm{m}$ and 3000 $\Omega \mathrm{m}$. Four different configurations per dipoledipole array and Wenner-Schlumberger array were made (Fig. 5):

a) two parallel high resistivity layers with the same length $(200 \mathrm{~m}), 10 \mathrm{~m}$ between layers,

b) two parallel high resistivity layers with different lengths (respectively $100 \mathrm{~m}$ and $200 \mathrm{~m}$ ), $10 \mathrm{~m}$ between layers,

c) two parallel high resistivity layers with the same length closer to each other $-5 \mathrm{~m}$,

d) one high resistivity layer (bottom layer).

The width of each layer was about $10 \mathrm{~m}$. The first layer was located at a depth of 31.6 to $41 \mathrm{~m}$ (for models 5A and 5B) or from 36.6 to 46 $\mathrm{m}$ (for model 5C). The second layer was located at a depth of 51 to $62 \mathrm{~m}$ (for models 5A-5D).
A

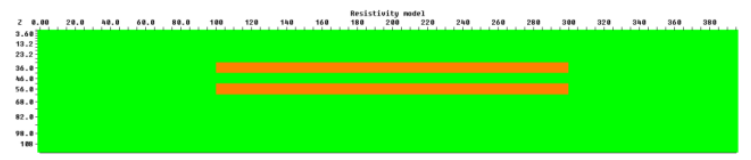

C.

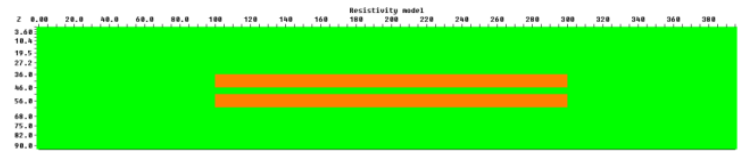

B

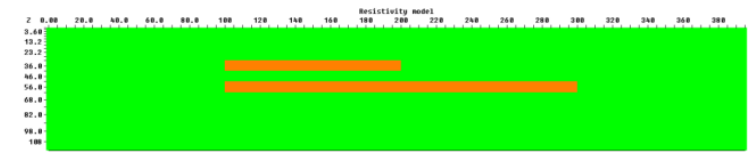

D

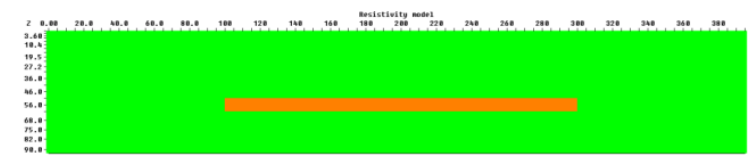

Fig.5. Models as displayed by Res2Dmod/Display. (A) Two parallel high resistivity (300/1000/3000 $\Omega$ m) layers in low resistivity medium $(55 \Omega \mathrm{m})$ with the same length $(200 \mathrm{~m})$. (B) Two parallel high resistivity layers $(300 / 1000 / 3000 \Omega \mathrm{m})$ in low resistivity medium $(55 \Omega \mathrm{m})$ with different lengths (respectively $100 \mathrm{~m}$ and $200 \mathrm{~m})$. (C) Two parallel high resistivity $(300 / 1000 / 3000 \Omega m)$ layers in low resistivity medium $(55 \Omega m)$ with the same length closer to each other. (D) One high resistivity (300/1000/3000 $\Omega \mathrm{m}$ ) layer (bottom layer) in low resistivity medium $(55 \Omega \mathrm{m})$ 
After modelling, inversion was carried out in the RES2DINV software. A few of the obtained results are shown in Figure 6.

The second profile was made on the basis of field data obtained from the landslide in Milówka. Two parallel subsurface layers with different resistivity values were assumed - first layer with thickness of $3.6 \mathrm{~m}$ and resistivity of $500 \Omega \mathrm{m}$ and the second layer with thickness of $12.8 \mathrm{~m}$ and resistivity of $60 \Omega \mathrm{m}$. Below is the low-resistivity $(90 \Omega \mathrm{m})$ layer in which the highresistivity $(300 \Omega \mathrm{m})$ layers lie at a certain angle - about $35^{\circ}$ (Fig. 7A). These layers represent flysch deposits that occur on the area of Prusów Mountain in the area of the Siedloki housing estate. Afterwards, the result was saved in RES2DINV format and processed with the software. Inverted model was compared to the resistivity cross-section obtained for the profile on Milówka landslide without topography (Fig. 7D) with the inverted result with the contour values based on obtained field data (Fig. 7C) and with its own contour scale (Fig. 7B).

\section{Results and discussion}

The geoelectric profile in Racibórz using the dipole-dipole array was conducted for a length of $400 \mathrm{~m}$ (Fig. 8). This length allowed for penetration of the geological medium to a depth of $95 \mathrm{~m}$. Landslide debris being a continuous surface layer of Quaternary sand deposits between 110 and $400 \mathrm{~m}$ of the profile is characterized by high electrical resistivity values (100-2000 $\Omega \mathrm{m})$. The thickness of this layer is from 2 to $18 \mathrm{~m}$ increasing in the west direction. Locally, there are very highresistivity lenses with resistivity up to $4040 \Omega \mathrm{m}$. They occur especially in the area of the landslide between 225 and $300 \mathrm{~m}$ of the profile's length. Below there is a low resistivity layer which resistivity ranges from a few to several dozen of $\Omega \mathrm{m}$. It is a layer of plastic clay with layers of fine-grained sand. Below this layer there is a layer of low-resistivity marl and clay.
The geoelectric profile using the WennerSchlumberger array was made for a length of $300 \mathrm{~m}$, which allowed the penetration of the geological medium to a depth of $33 \mathrm{~m}$ (Fig. 9). As for the previous profile, the first surface layer is a high-resistivity layer of Quaternary sand deposits (100-970 $\Omega \mathrm{m})$. The thickness of this layer is from 2 to $18 \mathrm{~m}$. Below there is a continuous layer of low-resistivity clay with sand (several-tens of $\Omega \mathrm{m}$ ), and under it there is a layer of marl and clay (20-70 $\Omega \mathrm{m})$.

Combined data set was created using Wenner-Schlumberger and dipole-dipole field data for the distance from 100 to $400 \mathrm{~m}$ (as the distance of Wenner-Schlumberger array profile) and provides supplementary information for data received separately from each array (Fig. 10). It was possible to separate five layers - a near-surface high-resistivity layer and four low-resistivity layers occurring under it.

The profile on the landslide in Milówka was made for the length of $400 \mathrm{~m}$ (Fig. 11). Only the Wenner-Schlumberger array was used due to the complicated terrain conditions and the inability to continue field measurements for the dipole-dipole array. This length of the profile allowed to achieve the depth of penetration of $68 \mathrm{~m}$. Based on the obtained resistivity model two low-resistivity layers were identified - the near surface layer with a thickness of approximately $14 \mathrm{~m}(50-200 \Omega \mathrm{m})$ and two underlying layers with resistivity from 70 to 300 $\Omega \mathrm{m}$. Very high resistivity lenses are present in the near surface layer (up to $2135 \Omega \mathrm{m}$ ). Within the second low-resistance layer there are flysch deposits lying at a certain angle. Symbol 'A' indicates a high-resistivity anomaly that is an artefact of inversion process carried out in the RES2DINV software and could not be eliminated during processing.

High resistivity lenses near surface are sandstone blocks and clay with rubble with systems of fissures and cracks developed on surface. The low-resistivity subsurface layer 

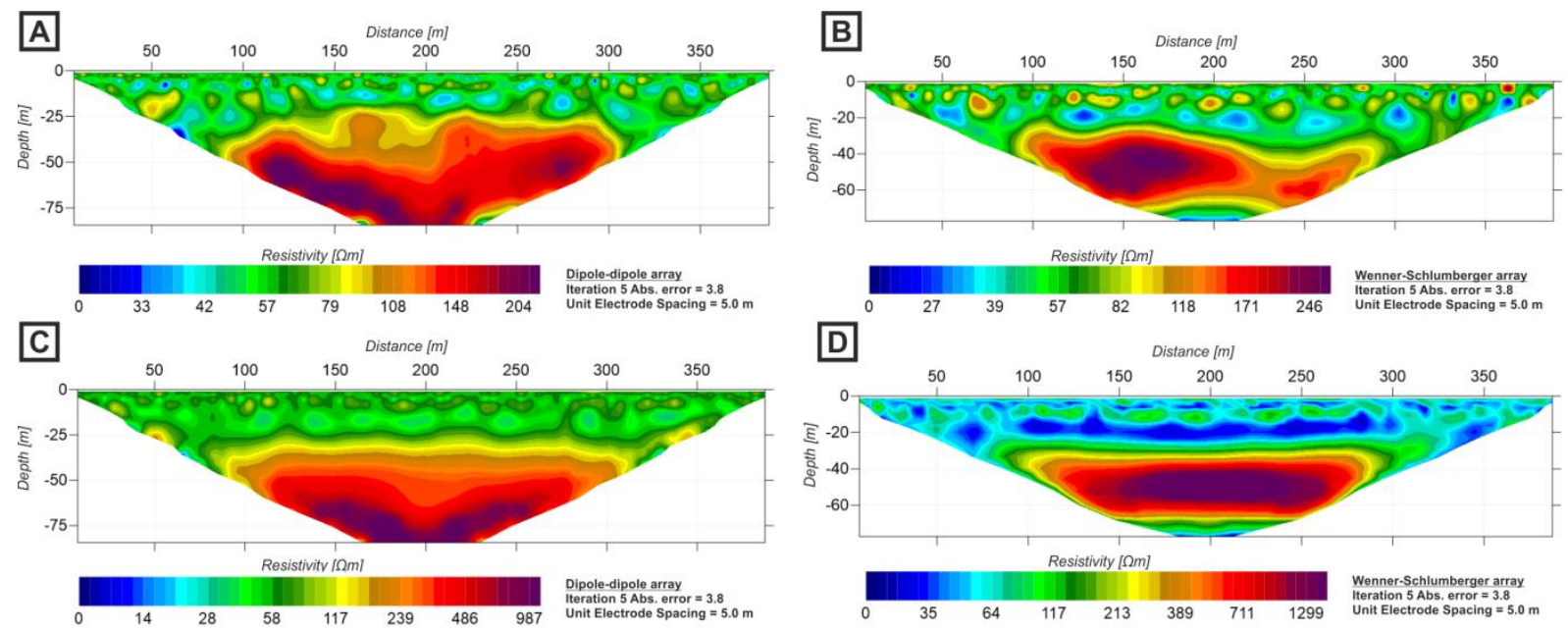

Fig.6. Four inverted results. (A) Dipole-dipole array. Forward model: two parallel high resistivity (300 $\Omega \mathrm{m})$ layers in low resistivity medium $(55 \Omega \mathrm{m})$ with the same length $(200 \mathrm{~m})$. (B) Wenner-Schlumberger array. Forward model: two parallel high resistivity layers $(300 \Omega \mathrm{m})$ in low resistivity medium $(55 \Omega \mathrm{m})$ with different lengths (respectively $100 \mathrm{~m}$ and $200 \mathrm{~m}$ ). (C) Dipole-dipole array. Forward model: two parallel high resistivity $(1000 \Omega \mathrm{m})$ layers in low resistivity medium $(55 \Omega \mathrm{m})$ with the same length $5 \mathrm{~m}$ to each other. (D) Wenner-Schlumberger array. Forward model: one high resistivity $(3000 \Omega \mathrm{m})$ layer in low resistivity medium $(55 \Omega \mathrm{m})$.

should be considered as a debris in which mass movements occur. In this layer, due to its thickness, reaching an average value of $14 \mathrm{~m}$ under the earth's surface (locally even up to 25 $\mathrm{m})$ there can be several slip surfaces of varying intensity, but it is not possible to distinguish them precisely. This resistivity layer should be considered as a flysch material, which has been highly mixed and/or crushed. It reduced its values of electrical resistivity significantly and prevented the detection of objects that can be identified as sandstone packets. The highresistivity lenses located below this layer should be considered as a flysch packet with the domination of sandstones reaching the slip surface. The dip of the layers in this area is approximately $25^{\circ}$ to the NE (inconsistent with the slip surface). Their disappearance is visible with the depth which is caused by the characteristic structure blocking the deeper current penetration and the upper low-resistivity layer working as an 'absorber' at larger electrode spacing. This interpretation aspect was presented on synthetic modelling (Fig. 7) made on the basis of available a priori knowledge regarding the geological structure of this area.
The geoelectric profile in Porąbka with the dipole-dipole array was conducted for a length of $200 \mathrm{~m}$ (Fig. 12). This length allowed for the penetration of the geological medium to a depth of $31 \mathrm{~m}$. The surface layer with a thickness from 2 to $6 \mathrm{~m}$ consists of clay and clay with rock rubble, pebbles and blocks being parts of flysch deposits. The highest value of electrical resistivity was reached in the surface layer $(1430 \Omega \mathrm{m})$.

The Wenner-Schlumberger array allowed to obtain a depth of penetration up to $33 \mathrm{~m}$ (Fig. 13). The highest value of electrical resistivity obtained for this array is $800 \Omega \mathrm{m}$ for highresistivity lenses in layers represented by shale with sandstone and occasionally siderite.

As in the case of Racibórz, for Porąbka combined data set was created using WennerSchlumberger and dipole-dipole field data (Fig. 14). Also for this resistivity model, it was possible to separate two lithological types of layers - a near surface clay and loam layer with flysch deposits and various types of clay lying under this layer. The highest resistivity value (about $1600 \Omega \mathrm{m}$ ) occurs within the lens located on the 40 meter of the geoelectric profile. 
A

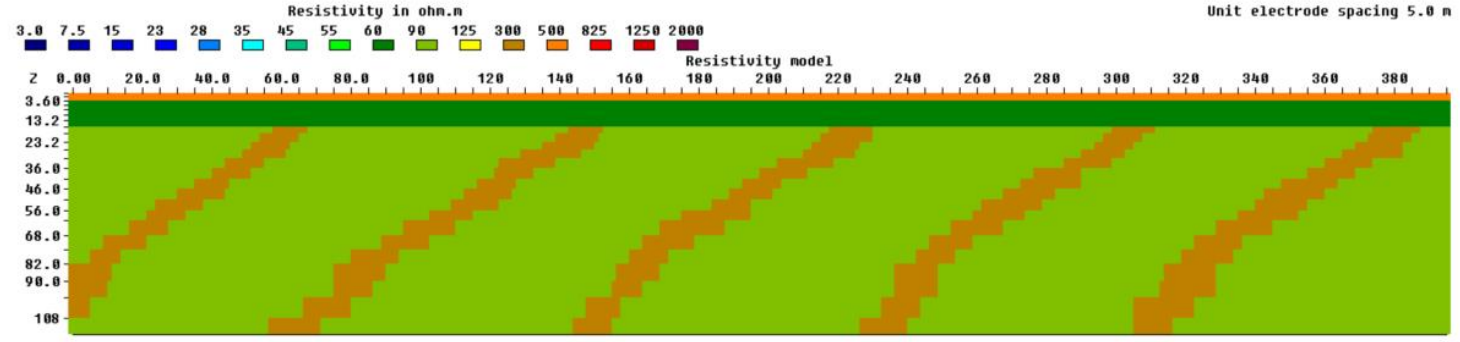

B
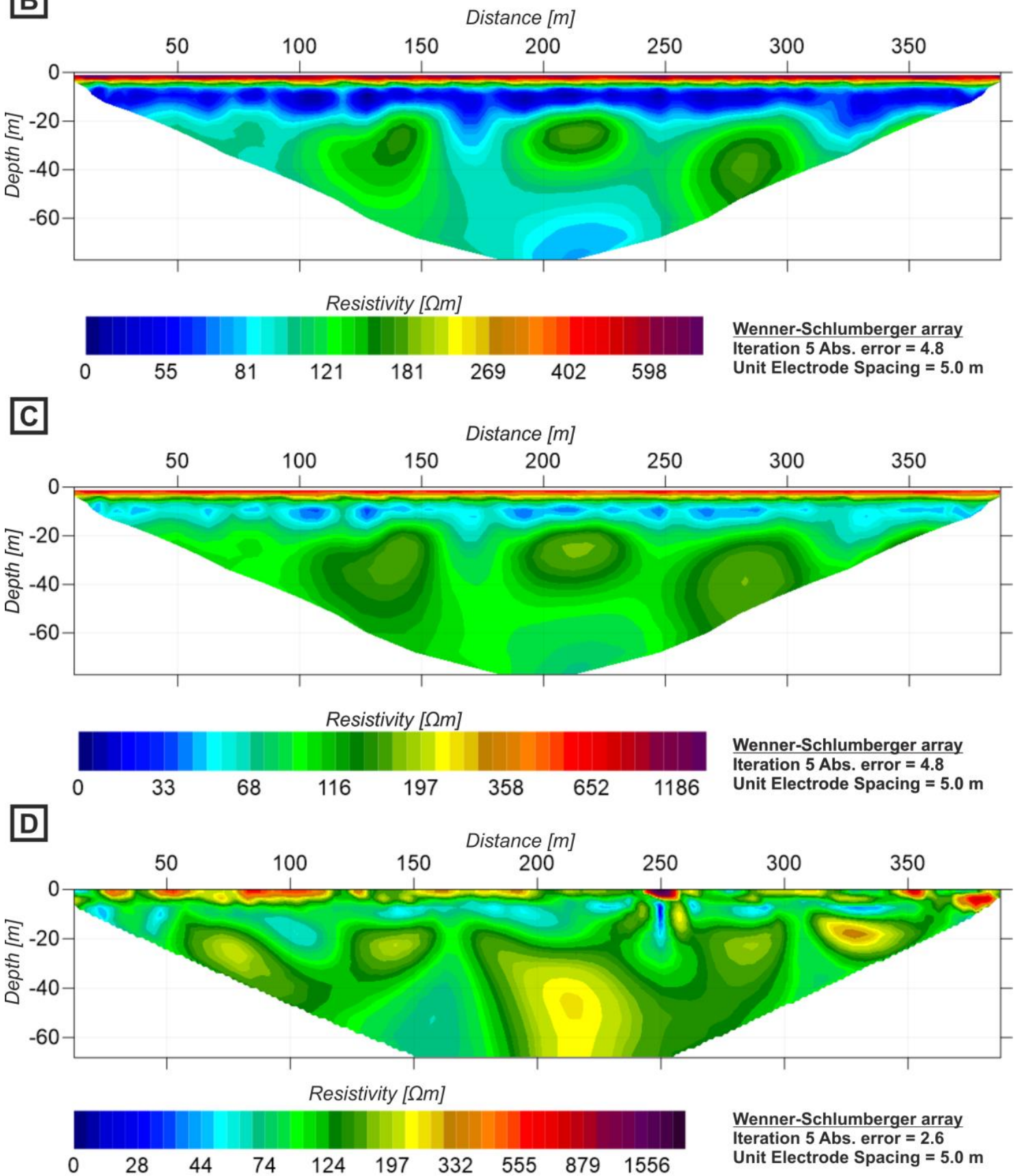

Fig.7. (A) Model as displayed by Res2Dmod/Display. (B) The inverted result. (C) The inverted result with the contour values based on obtained field data. (D) The resistivity cross-section obtained for the profile on Milówka landslide without topography. 


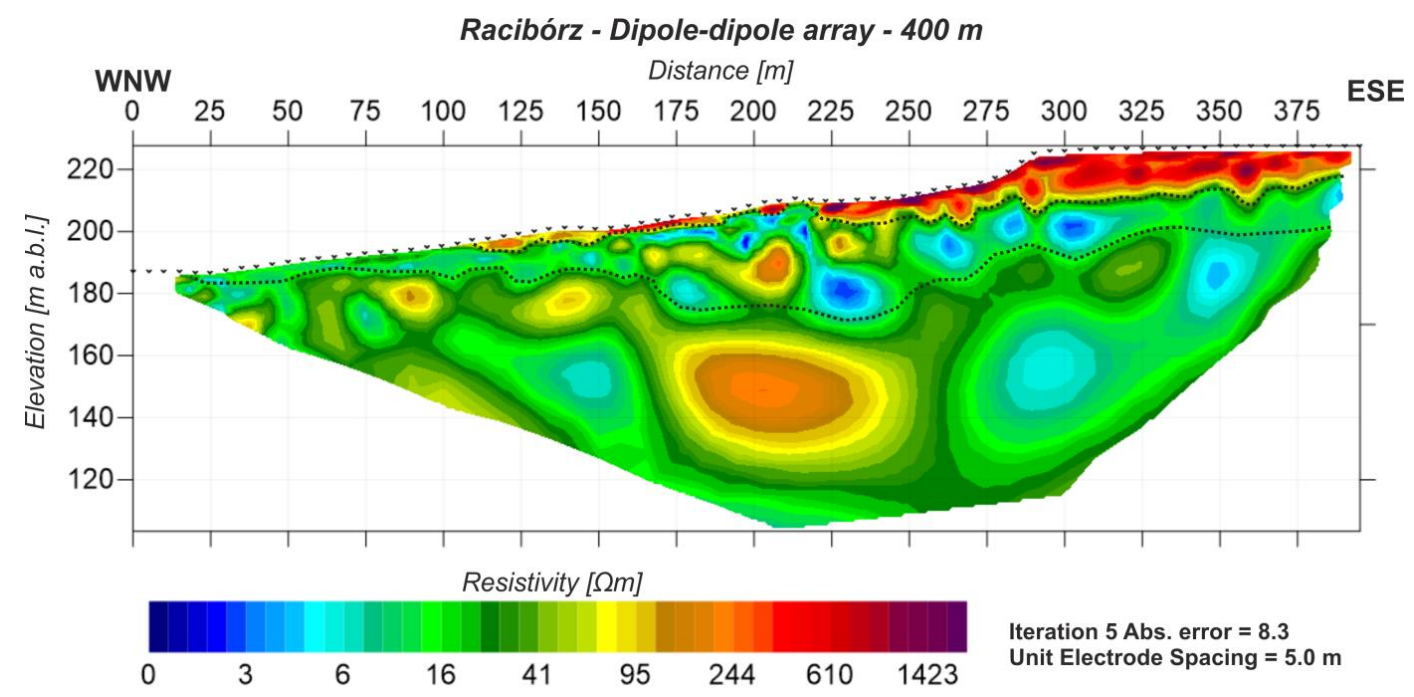

Fig.8. Resistivity model of ERT profile carried out on the Racibórz landslide in 2016. Dipole-dipole array. Dotted line: boundary of resistivity complex.

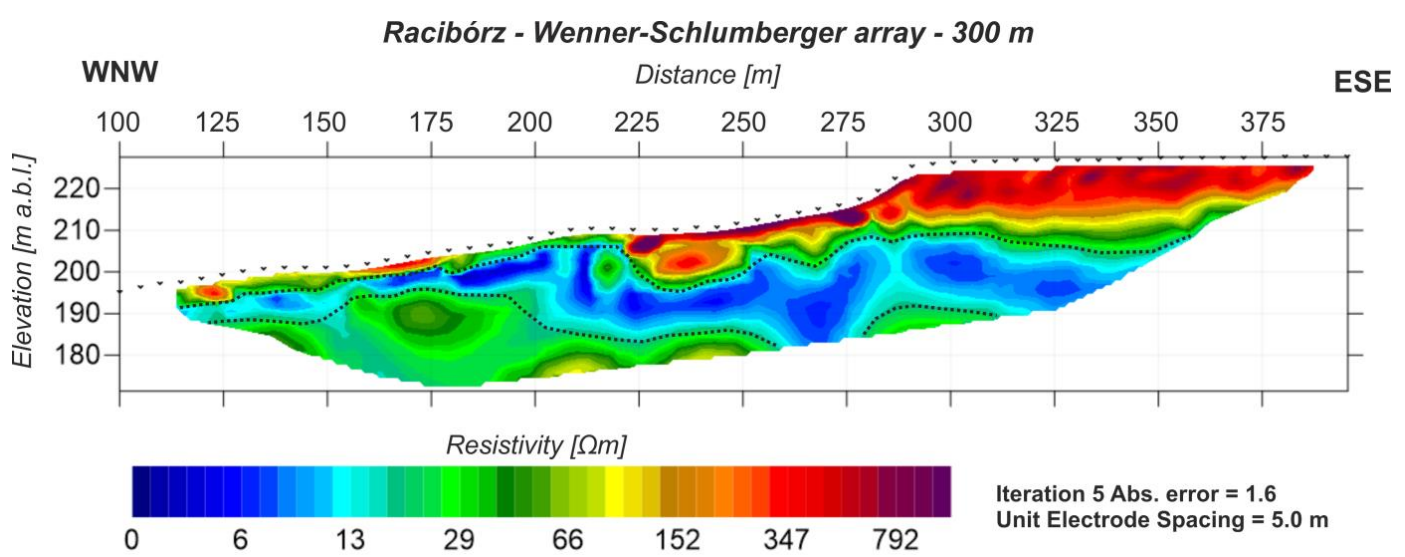

Fig.9. Resistivity model of ERT profile carried out on the Racibórz landslide in 2016. Wenner-Schlumberger array. Dotted line: boundary of resistivity complex.

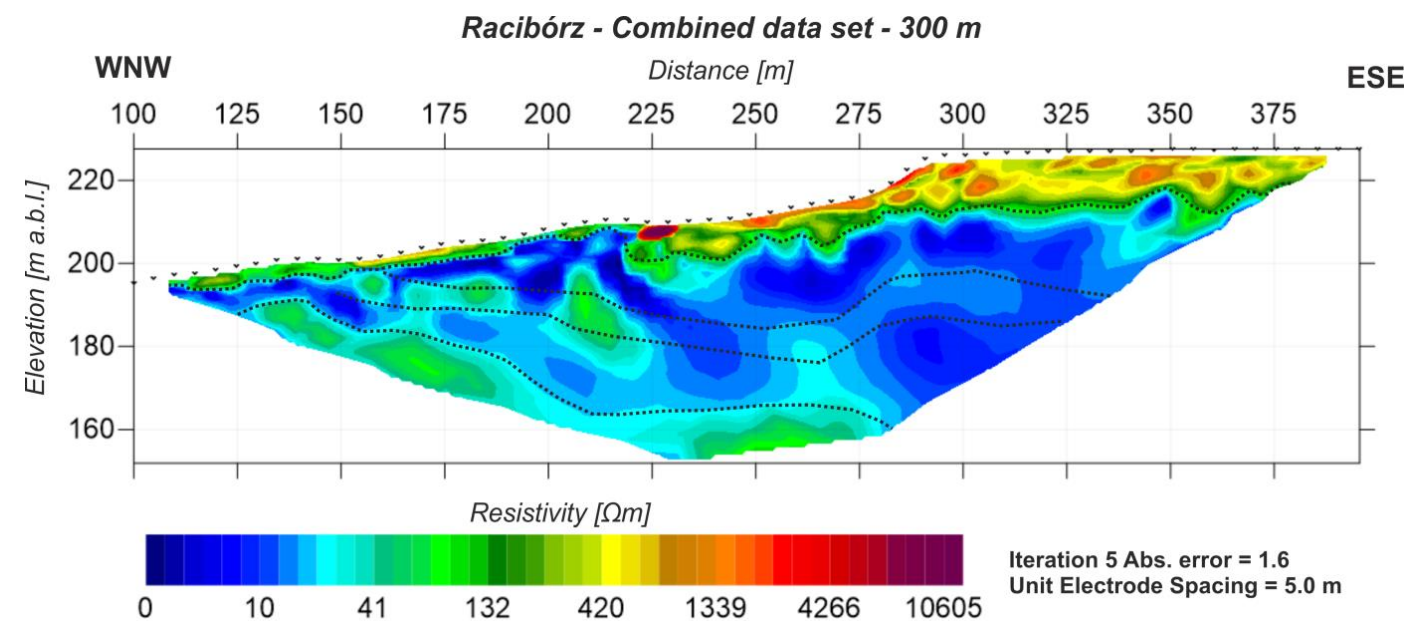

Fig.10. Resistivity model of ERT profile carried out on the Racibórz landslide in 2016. Combined data set. Dotted line: boundary of resistivity complex. 


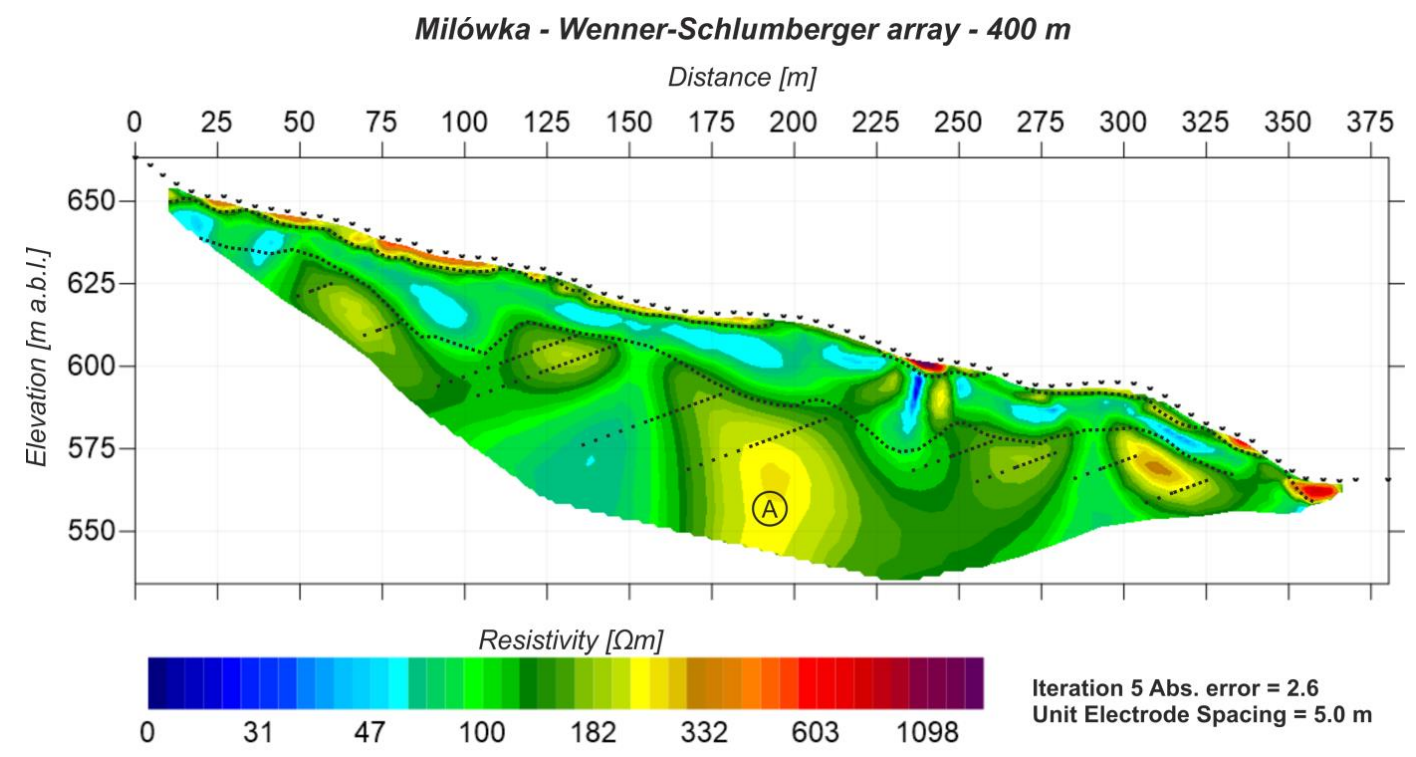

Fig.11. Resistivity model of ERT profile carried out on the Milówka landslide in 2015. Wenner-Schlumberger array. Dotted line: boundary of resistivity complex.

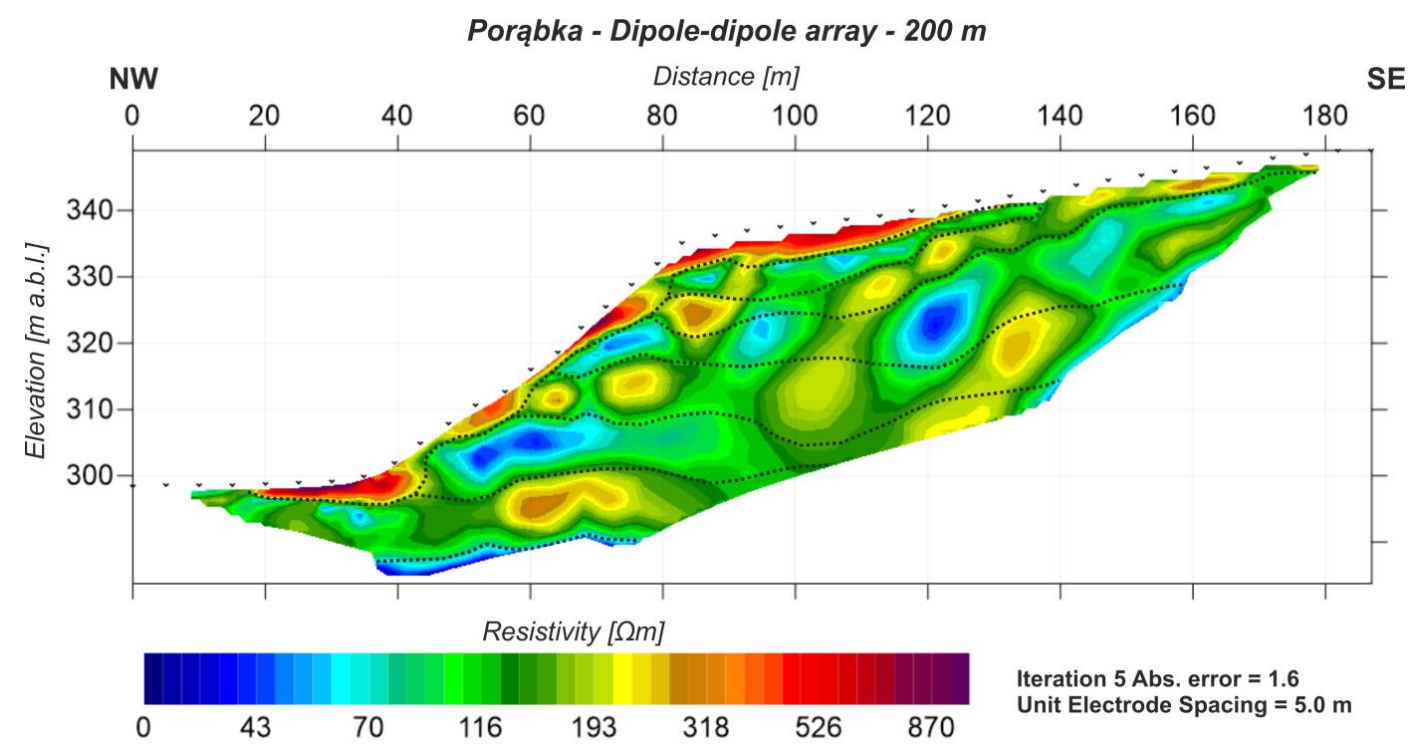

Fig.12. Resistivity model of ERT profile carried out on the Porąbka landslide in 2015. Dipole-dipole array. Dotted line: boundary of resistivity complex. Loosely dotted line: uncertain boundary of resistivity complex.

Wenner-Schlumberger and dipole-dipole arrays result in different resistivity models. In the case of the first mentioned array massive structures appear at greater depths while models based on dipole-dipole data create lenses of smaller sizes but in greater quantity. Layers of flysch dip in this area in the SE direction and the dip ranges from $25^{\circ}$ to $40^{\circ}$. In addition, lenses visible on the dipole-dipole models tend to be arranged in parallel directions while for Wenner-Schlumberger models inclination of massive anomalies vary from inclination of finer near-surface ones. Authors of this paper interpret high-resistivity anomalies of the dipole-dipole models as real layers of flysch, whereas in the case of deeper structures on Wenner-Schlumberger as an the effect of decreasing resolution with the depth. The discussed mechanism has been presented on synthetic modelling of two lenses lying close to each other (Fig. 5 and Fig. 6). Therefore, the stratification lines of the structures in Fig. 13 
have been carried out in a trend from dipoledipole model.

Combined data set gives better representation of near-surface structures on models, while in deeper parts it takes features of Wenner-Schlumberger array.

\section{Conclusions}

The landslide in Racibórz is currently stabilized by the forest and it is probable that there will be no violent events within it in the future, however creeping of the slope forced by its geological structure still has to be taken into account.

Landslide in Milówka due to the thickness of the debris, the character of the slip surface and the slope it is probable that future mass movements can occur. Due to the slip plane, which lies crosswise to the direction of sandstone packets, the material is subjected to lateral stress which leads to their crumbling. The area will achieve stabilization by slow

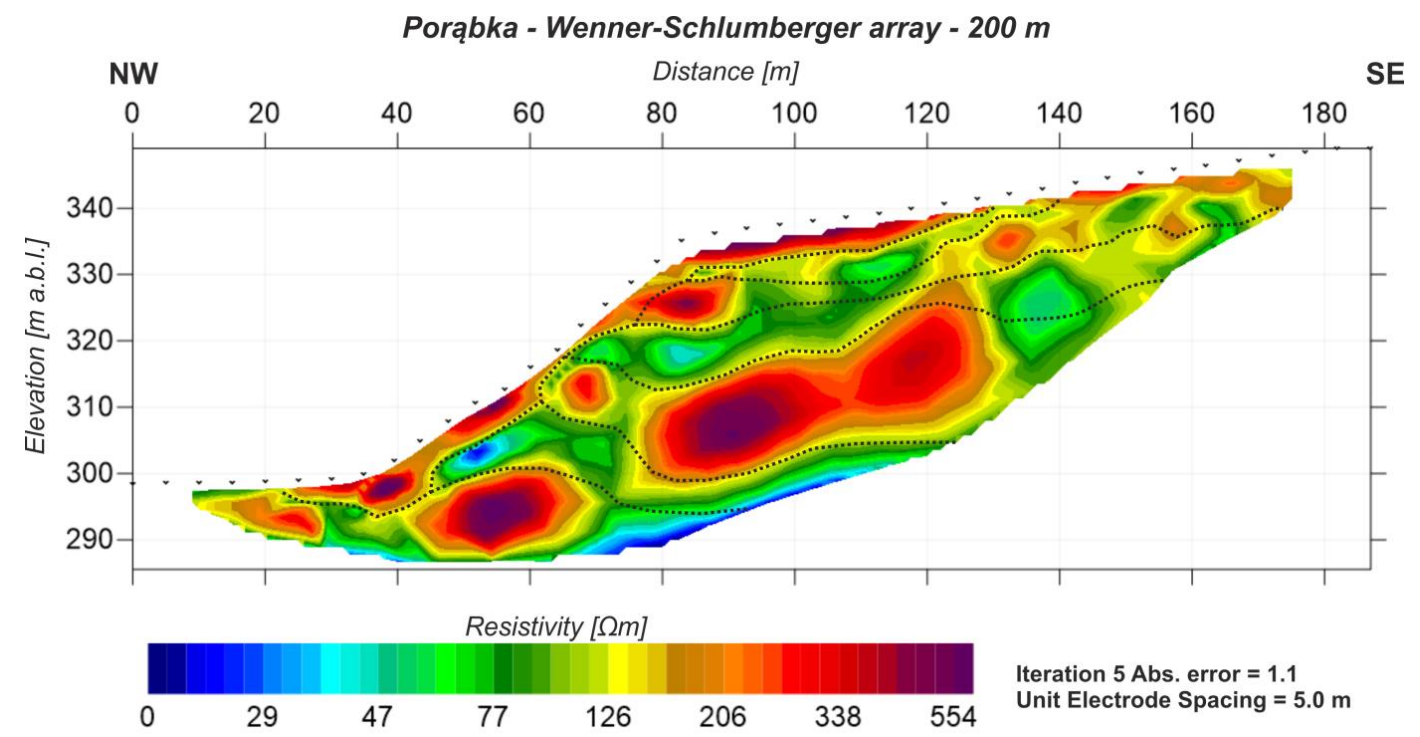

Fig.13. Resistivity model of ERT profile carried out on the Porąbka landslide in 2015. Wenner-Schlumberger array. Dotted line: boundary of resistivity complex.

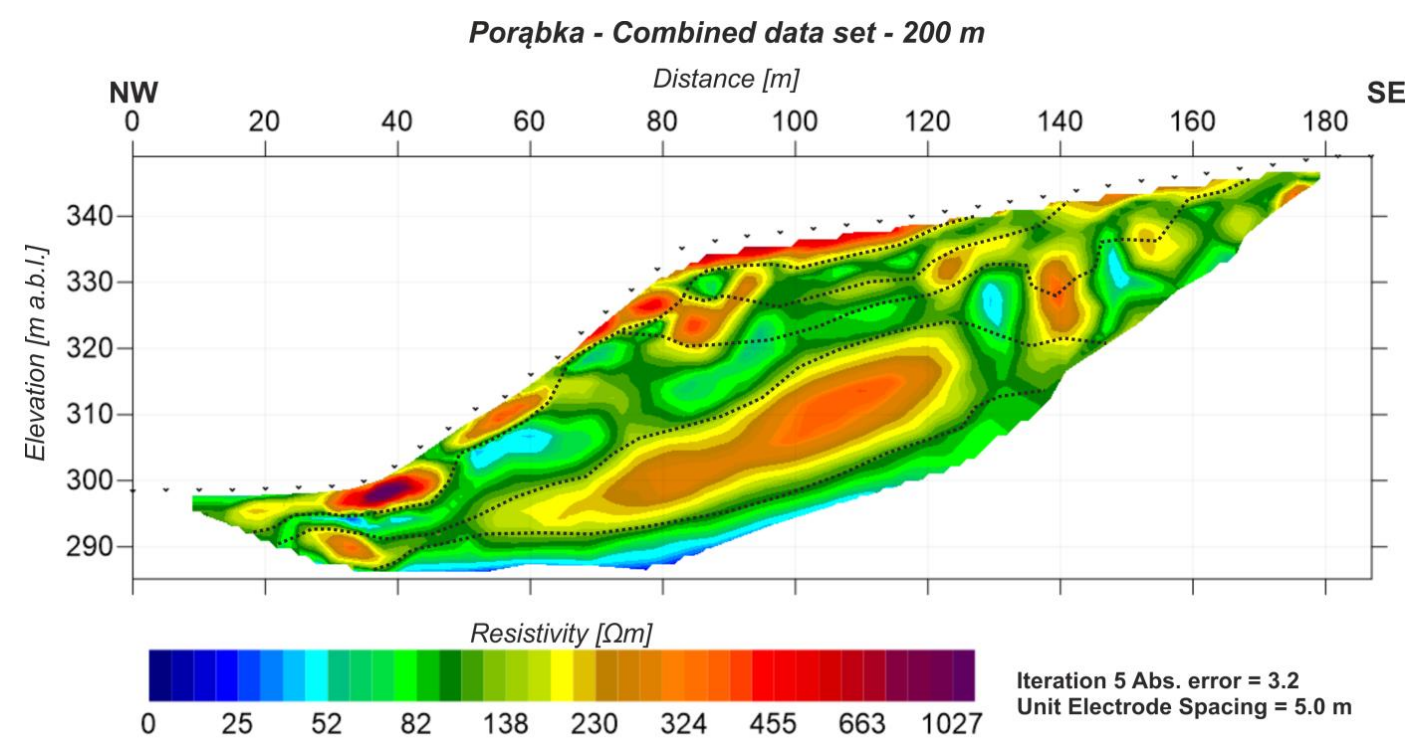

Fig.14. Resistivity model of ERT profile carried out on the Porąbka landslide in 2015. Combined data set.

Dotted line: boundary of resistivity complex. 
creeping, but during periods of heavy rainfall rapid landslide can occur

Landslide in Porąbka, due to the lenticular character of the structures interpreted as layers with the predominant presence of sandstones with fracture zones, should be considered to have the potential to form further slip surfaces that will include considerable amount of bedrock packets.

Combined data set in each case caused an increase in the resolution of models within the near-surface structures. In the case of deeper structures the Wenner-Schlumberger data imposed its resolution.

To understand the structures that appear on resistivity models in some cases carrying the forward modelling is necessary. Without this process the geophysical interpretation can be unreliable or even misleading. In the case of Milówka landslide it allowed check the reliability of the prepared resistivity model.

A wider approach to the processing of resistivity models involving the processing of large data sets, combining data from different measurement arrays, or forward modelling allow to obtain the more detailed information about geological structures that are present on ERT models and is the basis for a reliable analysis of resistivity cross-sections. Even if as a result of using additional forms of processing, the obtained models do not represent the geological structure accurately, they can provide useful information for the interpretation of basic resistivity models, especially in the near surface zone.

In order to determine the possibility of further mass movements, it is crucial to recognize the layer on which the slip occurs (slip surface, surface of rapture).

\section{References}

Bardel T. (2012) O antropogenicznych przyczynach powstania osuwiska na zboczu byłej kopalni iłów „Kantoria” w Tarnowie. Górnictwo i Geologia 7, 2, 35-47.
Burtan J., Sokołowski S., Sikora W., Żytko K. (1956) Szczegółowa mapa geologiczna Polski 1:50 000. Milówka Bielsko Biała (M-34-87A). Państwowy Instytut Geologiczny, Państwowy Instytut Badawczy, Oddział Karpacki, Kraków.

Calamita G, Perrone A., Bellanova J., Giocoli A., Lapenna V., Luongo R., Piscitelli S. (2013) Application of electrical resistivity tomographies for the geoelectrical characterization of Montaguto landslide (southern Italy), Poster Presentation. $32^{\circ}$ Convegno nazionale del Gruppo Nazionaledi Geofisica della Terra Solida, Trieste.

Chambers J.E., Wilkinson P.B., Kuras O., Ford J.R., Gunn D.A., Meldrum P., Pennington C.V.L., Weller A.L., Hobbs P.R.N., Ogilvy, R.D. (2011) Three-dimensional geophysical anatomy of an active landslide in Lias Group mudrocks, Cleveland Basin, UK. Geomorphology 125: 472-484, DOI: 10.1016/j.geomorph.2010.09.017.

Chen W., Li X., Wang Y., Chen G., Liu S. (2014) Forested landslide detection using LiDAR data and the random forest algorithm: A case study of the Three Gorges, China. Remote Sensing of Environment 152: 291-301, DOI: 10.1016/j.rse.2014.07.004.

Dostál I. Putiška R. Kušnirák D. (2014) Determination of shear surface of landslides using electrical resistivity tomography 44 , 2: 133-147, DOI: 10.2478/congeo-20140008.

Everett M.E. (2013) Electrical resistivity method. [In:] Near-surface applied Geophysics. Cambridge University Press, New York, second edition, 70-104.

Friedel S., Thielen A., Springman S.M. (2006) Investigation of a slope endangered by rainfall-induced landslides using 3D resistivity tomography and geotechnical testing. Journal of Applied Geophysics 60: 100-114, DOI: 10.1016/j.jappgeo.2006.01. 001. 
Grandjean G., Gourry J.C., Sanchez O., Bitri A., Garambois S. (2011) Structural study of the Ballandaz landslide (French Alps) using geophysical imagery. Journal of Applied Geophysics 75: 531-542, DOI: 10.1016/ j.jappgeo.2011.07.008.

Jebur M.N., Pradhan B., Tehrany M.S. (2014) Optimization of landslide conditioning factors using very high-resolution airborne laser scanning (LiDAR) data at catchment scale. Remote Sensing of Environment 152: 150-165, DOI: 10.1016/j.rse.2014.05.013.

Jomard H., Lebourg T., Tric E. (2007) Identification of the gravitational boundary in weathered gneiss by geophysical survey: La Clapière landslide (France). Journal of Applied Geophysics 62: 47-57, DOI: 10.1016/j.jappgeo.2006.07.003.

Loke M. H. (2015) Rapid 2-D Resistivity \& IP inversion using the least-squares method: Wenner $(\alpha, \beta, \gamma)$, dipole-dipole, inline polepole, pole-dipole, equatorial dipole-dipole, offset pole-dipole, Wenner-Schlumberger, gradient and non-conventional arrays. On land, aquatic and cross-borehole surveys. (Website: accessed 26th January, 2018 http://web.gps.caltech.edu/classes/ge111/D ocs/Res2dinv_Guide.pdf).

Loke M. H. (2016) Tutorial: 2-D and 3-D electrical imaging surveys. (Website: accessed 19th June, 2017 http://www.geotomosoft.com/downloads.p $\mathrm{hp})$.

Loke M.H., Barker R.D. (1996) Practical techniques for 3D resistivity surveys and data inversion. Geophysical Prospecting 44: 499-523, DOI: $\quad 10.1111 / \mathrm{j} .1365-2478$. 1996.tb00162.x.

Lowrie W. (2007) Fundamentals of Geophysics. Cambridge University Press, New York, second edition, 207-276.

Malehmir A., Saleem M.U., Bastani M. (2013) High-resolution reflection seismic investigations of quick-clay and associated formations at a landslide scar in southwest Sweden. Journal of Applied Geophysics 92:
84-102, DOI: 10.1016/j.jappgeo.2013.02. 013.

Marescot L., Monnet R., Chapellier D. (2008): Resistivity and induced polarization surveys for slope instability studies in the Swiss Alps. Engineering Geology 98: 1828, DOI: 10.1016/j.enggeo.2008.01.010.

Marinescu M., Cristea P., Maruntenau C., Mezincescu M. (2017) MASW Seismic Method in Brebu Landslide Area, Romania. IOP Conference Series: Earth and Environmental Science 95 032035, DOI:10.1088/1755-1315/95/3/032035.

Mizerski W. (2006) Osuwiska. [In:] Geologia dynamiczna. PWN, Warszawa (in Polish), 149-155.

Nescieruk P. Wójcik A. (1997) Szczegółowa mapa geologiczna Polski 1:50 000. 1012 Bielsko Biała (M-34-75-C). Państwowy Instytut Geologiczny, Państwowy Instytut Badawczy, Oddział Karpacki, Kraków.

Pánek T., Hradecký J., Šilhán K. (2008) Application of electrical resistivity tomography (ERT) in the study of various types of slope deformations in anisotropic bedrock: case studies from the flysch Carpathians. Studia Geomorphologica Carpatho-Balcanica 42, 57-73.

Parasnis D.S. (1979) Electrical methods. [In:] Principles of applied Geophysics. Chapman and Hall Ltd., London, third edition, 98130, DOI: 10.1007/978-94-009-5814-2.

Pasierb B. (2012) Techniki pomiarowe metody elektrooporowej. Czasopismo Techniczne 2-Ś 23, 109: 191-199.

Pilecki Z., Harba P. (2015): Wstępne wyniki badania budowy i właściwości osuwiska metodą interferometrii sejsmicznej $\mathrm{z}$ wykorzystaniem wysokoczęstotliwościowego szumu sejsmicznego. Zeszyty Naukowe Instytutu Gospodarki Surowcami Mineralnymi i Energią Polskiej Akademii Nauk 89: 63-75.

Pilecki Z., Pilecka E. (2016): Podstawowe zasady stosowania metod geofizycznych $\mathrm{w}$ badaniu osuwisk i terenów zagrożonych 
osuwiskami. Zeszyty Naukowe Instytutu Gospodarki Surowcami Mineralnymi i Energią Polskiej Akademii Nauk 92: 131140.

Poprawa D., Rączkowski W. (2003) Osuwiska Karpat. Przegląd Geologiczny 51, 8: 685692.

Rączkowski W., Wójcik A., Nescieruk P. (2016) Karta dokumentacyjna osuwiska wraz z opinią 24-17-092-002621. Państwowy Instytut Geologiczny, Państwowy Instytut Badawczy, Oddział Karpacki, Kraków.
Sass O., Bell R., Glade T. (2008) Comparison of GPR, 2D-resistivity and traditional techniques for the subsurface exploration of the Öschingen landslide, Swabian Alb (Germany). Geomorphology 93: 89-103, DOI: 10.1016/j.geomorph.2006.12.019.

Sikora R., Piotrowski A., Wilanowski S. (2011) Karta rejestracyjna osuwiska 2/Ra. Państwowy Instytut Geologiczny, Oddział Górnośląski, Sosnowiec.

Telford W.M., Geldart L.P., Sheriff R.E. (1990) Electrical Properties of Rocks and Minerals. [In:] Applied Geophysics. Cambridge University Press, New York, 283-292. 